\title{
Immediate Effects of Whole-Body Vibration Associated with Squatting Exercises on Hemodynamic Parameters in Sarcopenic Older People: A Randomized Controlled Trial
}

\author{
Fabiana Angélica de Paula ${ }^{1}\left(\mathbb{D}\right.$, Vanessa Amaral Mendonça ${ }^{2}\left(\mathbb{D}\right.$, Vanessa Kelly da Silva Lage ${ }^{1}(\mathbb{D}$, \\ Guilherme Pinto da Silva ${ }^{3}$, Hellen Cristina de Almeida ${ }^{1}$, Liliana Pereira Lima ${ }^{1}$, Joyce Noelly Vítor Santos ${ }^{3}{ }^{\circ}$, \\ Daniela Pereira de Castro ${ }^{4}$, Camila Franciele da Paixão ${ }^{4}$, Ana Luiza da Silva Nunes Teixeira Rodrigues ${ }^{4}(\mathbb{0}$, \\ Vinícius Cunha de Oliveira ${ }^{3}{ }^{\oplus}$, Pedro Henrique Scheidt Figueiredo ${ }^{3}$, Mario Bernardo-Filho ${ }^{5}{ }^{\mathbb{D}}$, \\ Ana Cristina Rodrigues Lacerda ${ }^{6}(\mathbb{D})$ and Redha Taiar $7, * \mathbb{B}$
}

1 Programa de Pós-Graduação Multicêntrico em Ciências Fisiológicas, Laboratório de Inflamação e Metabolismo, Universidade Federal dos Vales do Jequitinhonha e Mucuri, Diamantina 39100-000, Brazil; fabianaangelicadepaula@yahoo.com.br (F.A.d.P.); vanessakellysl@hotmail.com (V.K.d.S.L.); hellen.nut@gmail.com (H.C.d.A.); liliplima@hotmail.com (L.P.L.)

2 Programa de Pós-Graduação Multicêntrico em Ciências Fisiológicas, Programa de Pós-Graduação em Reabilitação e Desempenho Funcional, Programa de Pós-Graduação em Ciências da Saúde, Laboratório de Inflamação e Metabolismo, Universidade Federal dos Vales do Jequitinhonha e Mucuri,

check for updates

Citation: de Paula, F.A.; Mendonça, V.A.; Lage, V.K.d.S.; da Silva, G.P.; de Almeida, H.C.; Lima, L.P.; Santos, J.N.V.; de Castro, D.P.; da Paixão, C.F.; Rodrigues, A.L.d.S.N.T.; et al Immediate Effects of Whole-Body Vibration Associated with Squatting Exercises on Hemodynamic Parameters in Sarcopenic Older People: A Randomized Controlled Trial. Int. J. Environ. Res. Public Health 2021, 18, 11852. https://doi.org/ 10.3390/ijerph182211852

Academic Editor: Paul B. Tchounwou

Received: 23 September 2021

Accepted: 6 November 2021

Published: 12 November 2021

Publisher's Note: MDPI stays neutral with regard to jurisdictional claims in published maps and institutional affiliations.

Copyright: (c) 2021 by the authors. Licensee MDPI, Basel, Switzerland. This article is an open access article distributed under the terms and conditions of the Creative Commons Attribution (CC BY) license (https:// creativecommons.org/licenses/by/ $4.0 /)$.

\section{Diamantina 39100-000, Brazil; vaafisio@hotmail.com}

3 Programa de Pós-Graduação em Reabilitação e Desempenho Funcional, Universidade Federal dos Vales do Jequitinhonha e Mucuri, Diamantina 39100-000, Brazil; guilhermeps_ufvjm@hotmail.com (G.P.d.S.); joyce_noelly@outlook.com (J.N.V.S.); vcunhaoliveira@gmail.com (V.C.d.O.); phsfig@yahoo.com.br (P.H.S.F.)

4 Laboratório de Inflamação e Metabolismo, Universidade Federal dos Vales do Jequitinhonha e Mucuri, Diamantina 39100-000, Brazil; castrodanip@gmail.com (D.P.d.C.); kmilladtna@yahoo.com.br (C.F.d.P.); izarodrigues97@hotmail.com (A.L.d.S.N.T.R.)

5 Laboratório de Vibrações Mecânicas e Práticas Integrativas, Departamento de Biofísica e Biometria, Instituto de Biologia Roberto Alcântara Gomes and Policlínica Américo Piquet Carneiro, Universidade do Estado do Rio de Janeiro, Rio de Janeiro 20950-000, Brazil; bernardofilhom@gmail.com

6 Programa de Pós-Graduação Multicêntrico em Ciências Fisiológicas, Programa de Pós-Graduação em Reabilitação e Desempenho Funcional, Programa de Pós-Graduação em Ciências da Saúde, Laboratório de Fisiologia do Exercício, Universidade Federal dos Vales do Jequitinhonha e Mucuri, Diamantina 39100-000, Brazil; lacerdaacr@gmail.com

7 MATIM, Department of Sport Science, Université de Reims, CEDEX 2, 51687 Reims, France

* Correspondence: redha.taiar@univ-reims.fr

Abstract: Whole-body vibration (WBV) exercises have recently been introduced as a nonpharmacological therapeutic strategy for sarcopenic older people. The present study aimed to evaluate the effect of WBV exercise on hemodynamic parameters in sarcopenic older people. Forty older people, divided into groups of nonsarcopenic (NSG $=20$ ) and sarcopenic $(S G=20)$, participated in the study and were cross randomized into two interventions of eight sets of $40 \mathrm{~s}$ each, these being squatting with WBV and squatting without WBV. Heart rate (HR), peak heart rate (peak HR), systolic blood pressure (SBP), diastolic blood pressure (DBP), double product (DP), mean arterial pressure (MAP), and subjective perception of effort (SPE), were assessed at baseline, during, and after a single WBV session. The HR, peak HR, and DP variables were similar at baseline between groups. WBV exercise increased all the hemodynamic parameters both during and immediately after the intervention, in both groups (SG and NSG). The MAP values were similar at baseline between groups; however, in the NSG there was a significant increase during and immediately after the squatting with WBV intervention $(p<0.05)$. The HR behavior, in both groups, showed that there was an increase in HR after the first set of exercises with vibration and this increase was maintained until the final set. The absence of adverse effects of WBV exercise on the cardiovascular system and fatigue suggests this exercise modality is adequate and safe for sarcopenic older people.

Keywords: sarcopenia; older people; whole-body vibration; physical exercise; hemodynamic responses 


\section{Introduction}

Sarcopenia is a progressive and generalized disease of skeletal muscle, recognized in ICD-10 (International Code of Diseases), which is associated with a greater likelihood of adverse outcomes, including falls, fractures, physical disability, mortality [1], and higher health costs [2]. The incidence of sarcopenia increases with age [3], and depending on the environment [4], can affect up to $33 \%$ of the population of older people living in the community [5], and up to $68 \%$ of individuals living in long-term care institutions [6].

The progressive loss of skeletal muscle mass occurring with aging may be associated with an inadequate supply of blood flow to the skeletal muscle. This plays an important role in the development of sarcopenia, as demonstrated in a study in which the blood pressure (BP) variability index was significantly higher at rest in both male and female participants in the group with the lowest appendicular skeletal muscle mass (ASM) [7]. Studies show that aging attenuates coronary blood flow and myocardial perfusion and predisposes older people to adverse cardiac events [8,9]. Moreover, aortic diastolic blood pressure (DBP) response to muscle metaboreflex activation is attenuated in older people with dynapenia but positively affects walking performance in nondynapenic older people [10]. Therefore, hemodynamic changes play an important role in the development of sarcopenia [7].

Thus, sarcopenia can be considered one of the most important causes of reduced cardiorespiratory fitness in older people, especially the frail [11,12]. Moreover, it is associated with cardiovascular risk factors such as altered endothelial function, reduced exercise tolerance, effects on BP, and reduced heart-rate recovery in sarcopenic older people with heart failure [13].

Physical exercise, nutrition, hormone replacement, and lifestyle interventions are among the forms of treatment for sarcopenia [14-16]. Interventions that promote a physically active lifestyle, reduced sedentary behavior and increased energy expenditure are recommended for the treatment and prevention of sarcopenia $[17,18]$. Although traditional resistance training is often recommended, evidence indicates that the effects of resistance exercise can be optimized if combined with whole-body vibration (WBV) [19]. A study noted improvement in muscle power by adding vibration therapy to conventional resistance exercise [20]. WBV has been introduced as a complementary and viable form of exercise for frail older people [21-23], and especially for sarcopenic older people [24,25].

The physiological effects of WBV are explained by greater muscle activation, leading to better cardiorespiratory responses and muscle activity during exercise [20,26-28]. Some of these immediate physiological effects, such as increased heart rate (HR) during WBV, are supported by studies in sedentary older people [26,28], in older people with chronic obstructive pulmonary disease (COPD) [29], and in maintenance of cardiovascular responses in older people with metabolic syndrome [30].

Currently, there is no clear consensus on clinical intervention for sarcopenia [25,31]. Furthermore, the majority of sarcopenic older people have a sedentary lifestyle and are frequently reluctant to start a conventional exercise program. WBV may represent a form of well-tolerated exercise for this population. However, there are no studies evaluating the immediate effects of WBV on hemodynamic responses in sarcopenic older people.

Thus, this study aimed to evaluate the effects of one session of squatting exercises with and without WBV on hemodynamic parameters in sarcopenic older people. The hypothesis is that a single WBV session promotes changes in hemodynamic parameters in individuals with sarcopenia and that there is a difference between the squatting exercise with and without WBV.

\section{Materials and Methods}

\subsection{Participants and Sample Size Estimation}

A crossover randomized controlled trial was conducted between February 2018 and January 2020 with older people living in the community. Participants were recruited through verbal invitation, leaflets, and visits to basic health units and physicians' offices, or through communication (internet, radio). The inclusion criteria were people aged 60 
or over of either sex, who met the criteria of sarcopenia diagnosis, according to relative skeletal muscle index (RSMI) cutoff points described by the European Working Group Consensus on Sarcopenia in Older People-EWGSOP [1]. Exclusion criteria were (1) presence of acute illness; (2) decompensated chronic disease; (3) taking Beta-blocker medication; (4) participation in any physical training program three months prior to the beginning of the assessments; (5) contraindication to the vibrating platform, such as epilepsy, gallstones or kidney stones, neuromuscular and neurodegenerative diseases, stroke, serious heart disease, or those with an implant, bypass, or stent; and (6) cognitive impairment.

The required sample size was determined according to the study by Ribeiro et al. [32]. Considering an effect size of $0.47, \alpha=0.05$, and power of 0.94 , found by two-way ANOVA, the estimated sample size was 18 individuals per group (non-sarcopenic and sarcopenic). The value obtained was increased by $11 \%$ to suppress potential losses during the execution of the project, with 20 individuals per group, totaling 40 participants. The distribution of participants between the groups was controlled by sex, age, and drug class, to minimize the influence of confounding variables.

\subsection{Diagnostic Criteria to Sarcopenia}

Participants were evaluated using dual-energy X-ray absorptiometry (DXA) (Lunar, DPX, Madison, WI, USA) for body composition measurements, and for the diagnosis of sarcopenia, relative skeletal muscle index (RSMI) cutoff points were considered using Appendicular skeletal muscle mass (ASM) divided by height squared. The cutoff point for the diagnosis of sarcopenia was $<7.0 \mathrm{~kg} / \mathrm{m}^{2}$ for men and $<5.5 \mathrm{~kg} / \mathrm{m}^{2}$ for women [1,33].

\subsection{Procedures}

\subsubsection{Body Mass Index (BMI)}

BMI was calculated by dividing body mass $(\mathrm{kg})$ by the square of height (meters), adopting the cutoff point for eutrophic BMI between $22 \mathrm{~kg} / \mathrm{m}^{2}$ and $27 \mathrm{~kg} / \mathrm{m}^{2}$ [34].

\subsubsection{Body Composition Assessment}

Total body mass, fat mass, and lean mass were assessed using DXA. Fat mass and lean mass were assessed through total body analysis and by body segment (upper, lower, and arms and legs).

\subsubsection{Functionality Assessment}

To assess functionality, the following tests were performed: walking speed over $4 \mathrm{~m}$, where the cutoff point used was $\leq 0.8 \mathrm{~m} / \mathrm{s}$ [1]; Short Physical Performance Battery (SPPB), which is a functional performance test composed of standing static and balancing in three positions (side-by-side stands, semi-tandem and tandem); $4 \mathrm{~m}$ gait speed test; and 5STS (timed test to sit and stand up from a chair without arms five times) [35]. The cutoff point in SPPB is $\leq 8$ [1] for a diagnosis suggestive of functional impairment. In addition, handgrip strength (HS) was also measured, being assessed using the Jamar ${ }^{\circledR}$ dynamometer, with cutoff points for sarcopenia for low handgrip strength being $<27 \mathrm{kgf}$ and $<16 \mathrm{kgf}$ for men and women, respectively [1]. The assessors were blinded in relation to the groups in which the participants were included.

\subsection{Interventions}

All the experimental procedures were conducted in the same place and on a set schedule. Participants were stratified according to the diagnosis of sarcopenia into the nonsarcopenic group (NSG) and sarcopenic group (SG). The order of execution of the two experimental situations was randomized through a simple draw, in which the protocols were marked by numbers, whereby number 1 corresponded to squatting with WBV and number 2 to squatting without WBV. The participants were randomly allocated to one of the protocols, and after a washout period of one week, they performed the other intervention. 
All participants performed the intervention protocol (WBV stimulus) and the control (squat without WBV).

\subsubsection{Exercise Intervention with WBV}

The vibration exposure consisted of performing dynamic squatting exercises ( 8 sets of $40 \mathrm{~s}$ ) with a vibration stimulus (frequency of $40 \mathrm{~Hz}$ and amplitude of $4 \mathrm{~mm}$ ) performed on a commercial model of a vibration platform (VP) (FitVibe ${ }^{\circledR}$, GymnaUniphy NV, Bilzen, Belgium) [26]. This vibration frequency and amplitude were selected due to prototype renders of an acceleration range of 2-5 $\mathrm{g}$ [27]. The participants were instructed to perform $3 \mathrm{~s}$ of isometric flexion of $60^{\circ}$ and $3 \mathrm{~s}$ of isometric flexion of the knees at $10^{\circ}$. Between the sets, the participants were instructed to remain at rest for $40 \mathrm{~s}$ in the orthostatic position on the turned-off VP. The $60^{\circ}$ angle was measured for each volunteer using a universal goniometer before initiating the exercise sets. A barrier was placed at the gluteal region to limit the flexion degree of the knees $[32,36]$. The exercise execution time was around $10 \mathrm{~min}$.

\subsubsection{Exercise Intervention without WBV}

The without-WBV intervention was performed with the same dynamic squatting exercises (8 sets of $40 \mathrm{~s}$ ) with the VP turned off. The participants were instructed to perform $3 \mathrm{~s}$ of isometric flexion of $60^{\circ}$ and $3 \mathrm{~s}$ of isometric flexion of the knees at $10^{\circ}$. Between the sets, the participants were instructed to remain at rest for $40 \mathrm{~s}$ in the orthostatic position on the turned-off VP. The $60^{\circ}$ angle was measured for each volunteer using a universal goniometer before initiating the exercise sets. A barrier was placed at the gluteal region to limit the flexion degree of the knees $[32,36]$. The exercise execution time was around $10 \mathrm{~min}$.

\subsection{Data Collection}

\subsubsection{Hemodynamic Measurements}

At baseline, during, and in the first minute after exercise, systolic blood pressure (SBP), diastolic blood pressure (DBP), HR, and peak HR were measured. Double product (DP) was obtained by multiplying SBP and HR $[37,38]$. The values of the SBP and DBP measurements were used to calculate mean arterial pressure (MAP) [39]. The percentage of maximum heart rate (HRmax) predicted for age was calculated according to the formula $(\mathrm{HR} \max =220-$ age $)[40]$.

\subsubsection{Subjective Perception of Effort (SPE)}

At the beginning and immediately after the end of each exercise session, participants assigned a value to the SPE on the modified Borg scale. This is a scale from 0 to 10, which represents a linear increase with exercise intensity, where zero means no fatigue and 10 is maximum fatigue. [41].

\subsection{Statistical Analysis}

Data were analyzed using SPSS version 22.0 and GraphPad Prism 7.0. The data normality was verified using the Shapiro-Wilk test. Descriptive analysis was expressed as mean, standard deviation, and a 95\% confidence interval (95\% CI). Between-group comparisons for baseline data were performed through unpaired $t$-test or Mann-Whitney test, as appropriate. Within-group and between-group differences on hemodynamics postintervention outcomes were analyzed using two-way ANOVA with Bonferroni post hoc test. The power and effect size were calculated using Gpower 3.1 software. The level of statistical significance was set at $5 \%$. 


\section{Results}

All 40 participants completed the study and were included in the analysis as allocated (intention-to-treat analysis). The same participant went through both protocols, in a randomized and crossed way (Figure 1).

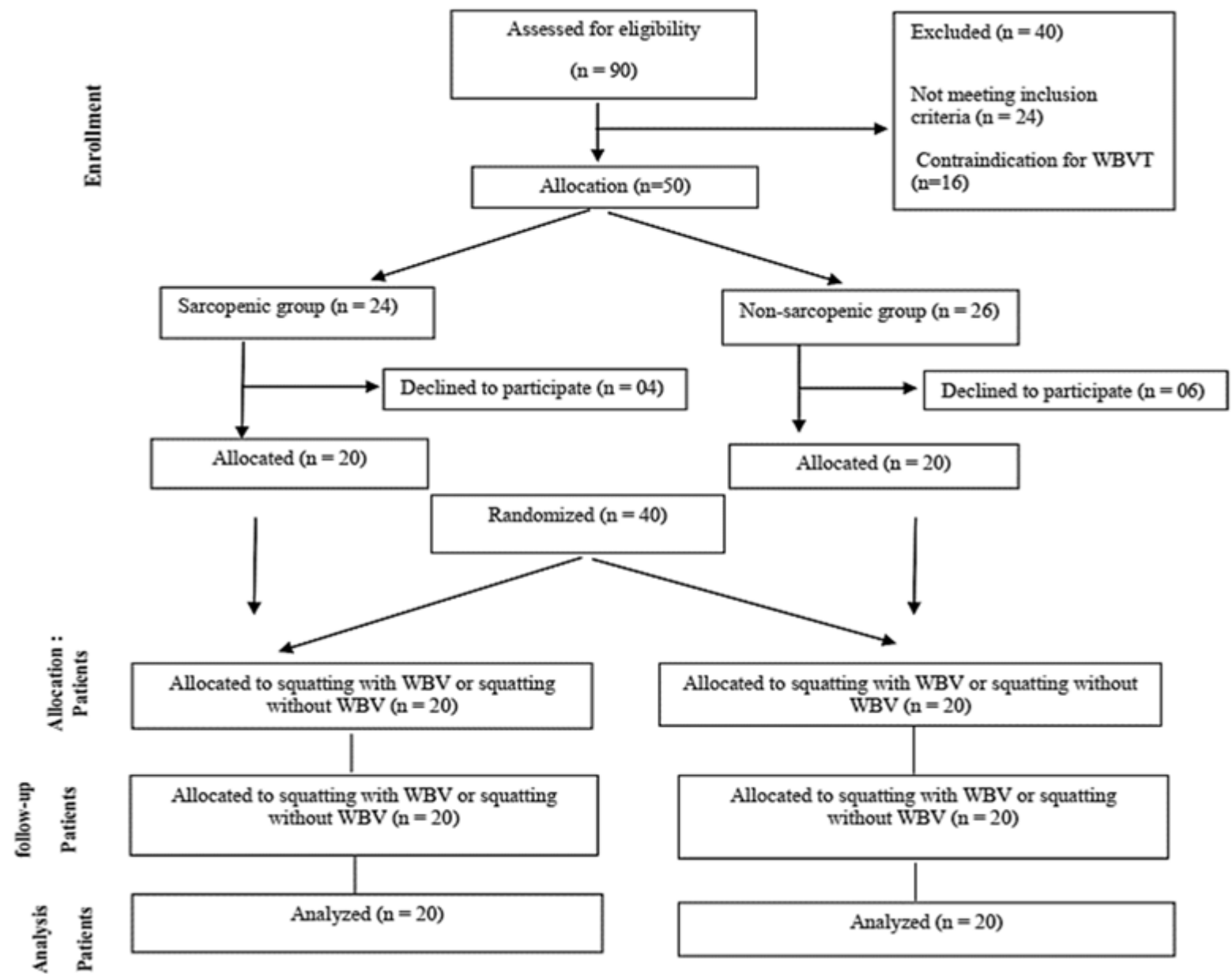

Figure 1. Flowchart of the participants.

\subsection{Characteristics of the Participants}

Forty older people, 20 women and 20 men, participated in the study. As expected, there were significant differences in body composition variables. The SG had a lower fat mass when compared to the NSG $(p<0.01)$. As for RSMI, when stratified by sex, men and women in the SG had lower RSMI when compared with those in the NSG $(p<0.01)$. The SG showed worse performance on the Sit-to-Stand test (5STStest) $(p=0.01)$ when compared to the NSG. In both groups, $45 \%$ of participants were taking antihypertensives, and $50 \%$ and $55 \%$ of nonsarcopenic and sarcopenic participants, respectively, were taking no medication (Table 1).

\subsection{Hemodynamic Responses in the Situations with and without WBV in NSG and SG}

The HR (Figure 2A), peak HR (Figure 2B), and DP (Figure 2F) variables were similar at baseline between the groups. WBV exercise increased all the hemodynamic parameters (during and immediately after) in both groups (SG and NSG). There were no differences for SBP (Figure 2C), DBP (Figure 2D), and SPE (Figure 2G) for both groups in squatting exercise interventions with and without WBV. The MAP was similar at baseline between groups; however, in the NSG there was a significant increase during and immediately after the squatting exercises with WBV $(p<0.05)$ (Figure 2E). 
Table 1. Clinical, demographic and functional characteristics of participants at baseline.

\begin{tabular}{|c|c|c|c|}
\hline Characteristics & $\begin{array}{c}\text { NSG } \\
(n=20)\end{array}$ & $\begin{array}{c}\text { SG } \\
(n=20)\end{array}$ & $p$-Value \\
\hline \multicolumn{4}{|l|}{ Demographic and body composition } \\
\hline Age (years) & $72.4(69.1-75.8)$ & $71.6(67.7-75.5)$ & 0.73 \\
\hline Sex (Men/Women) & $11 / 9$ & $11 / 9$ & \\
\hline $\operatorname{BMI}\left(\mathrm{kg} / \mathrm{m}^{2}\right)$ & $24.9(23.7-26.2)$ & $21.2(20.2-22.2)$ & 0.01 \\
\hline $\mathrm{BF}(\%)$ & $32.8(29.8-35.8)$ & $31.7(27.8-35.7)$ & 0.65 \\
\hline Lean mass (kg) & $39.4 .1(35.9-42.8)$ & $33.4(30.1-36.6)$ & 0.01 \\
\hline Fat mass (kg) & $19.1(17.2-20.9)$ & $15.5(13.4-17.7)$ & 0.01 \\
\hline RSMI Men & $8.0(7.5-8.6)$ & $6.5(6.1-6.9)$ & 0.01 \\
\hline RSMI Women & $6.4(5.9-6.7)$ & $5.2(5.0-5.4)$ & 0.01 \\
\hline \multicolumn{4}{|l|}{ Strength and functional tests } \\
\hline$S P P B$ (points) & $10.7(10.3-11.2)$ & $10.1(9.5-10.8)$ & 0.21 \\
\hline 5STS $(\mathrm{s})$ & $9.1(8.3-9.8)$ & $10.9(9.8-12.1)$ & 0.01 \\
\hline Walking speed (m/s) & $1.9(1.7-2.0)$ & $1.7(1.5-1.8)$ & 0.06 \\
\hline Handgrip strength (kgf) & $34.8(30.7-39.0)$ & $31.8(27.0-36.5)$ & 0.31 \\
\hline Men Handgrip strength (kgf) & $41.2(34.5-47.9)$ & $41.2(38.9-43.4)$ & 0.98 \\
\hline Women Handgrip strength (kgf) & $29.6(26.4-32.8)$ & $24.1(19.6-28.6)$ & 0.05 \\
\hline \multicolumn{4}{|l|}{ Medicines } \\
\hline Antihypertensives & $9(45 \%)$ & $9(45 \%)$ & \\
\hline Statins & $1(5 \%)$ & $3(15 \%)$ & \\
\hline Oral antidiabetics & $0(0 \%)$ & $1(5 \%)$ & \\
\hline Anticoagulant & $1(5 \%)$ & $0(0 \%)$ & \\
\hline Antirheumatics & $0(0 \%)$ & $1(5 \%)$ & \\
\hline Antidepressants & $1(5 \%)$ & $0(0 \%)$ & \\
\hline None & $10(50 \%)$ & $11(55 \%)$ & \\
\hline
\end{tabular}

Values are means (95\% CI), number, and percentage. NSG: Nonsarcopenic group. SG: Sarcopenic group. BMI: Body Mass Index, BF: Body Fat, RSMI: Relative Skeletal Muscle Mass Index, SPPB: Short Physical Performance Battery, STS: Sit-to-Stand test. Bold values denote statistical significance at the $p<0.05$ level.

\subsection{Heart Rate (HR) Behavior after Each Set of Exercises in Interventions with and without WBV} in NSG and SG

The visual analysis of the HR behavior graph demonstrates that in the NSG, the HR value increased after the first set of squatting exercises with $\mathrm{WBV}$, and this behavior was generally maintained until the last series of the exercise session (Figure 3A). Only a slight variation was observed in the sixth set of exercises, with a drop in the HR value. In the SG, it was observed that the HR value during pre-exercise (rest) was lower, and from the first set of squatting exercises with WBV there was an increase which remained without a further fall until the final set of exercises (Figure 3B).

The HR values in the squatting exercises without WBV in both groups remained lower compared to with squatting exercises with $\mathrm{WBV}$, and few variations were observed (Figure 3A,B).

\subsection{Comparison of Hemodynamic Parameters between the Interventions in the NSG and the SG}

To compare changes in hemodynamic variables in response to exercise, delta comparisons (during-rest) were performed, as indicated by $\Delta$. There were no differences at baseline between the NSG and the SG for hemodynamic parameters (HR, peak HR, SBP, DBP, MAP, and DP); however, the addition of WBV promoted a significant increase in peak HR in both groups $(p<0.000)$ when compared with the squatting exercise without WBV. In the NSG, the addition of vibration to the squatting exercise promoted a significant increase in HR $(p<0.003)$, MAP $(p<0.005)$, and DP $(p<0.003)$ when compared with the squatting exercise without vibration (Tables 2 and 3 ). 

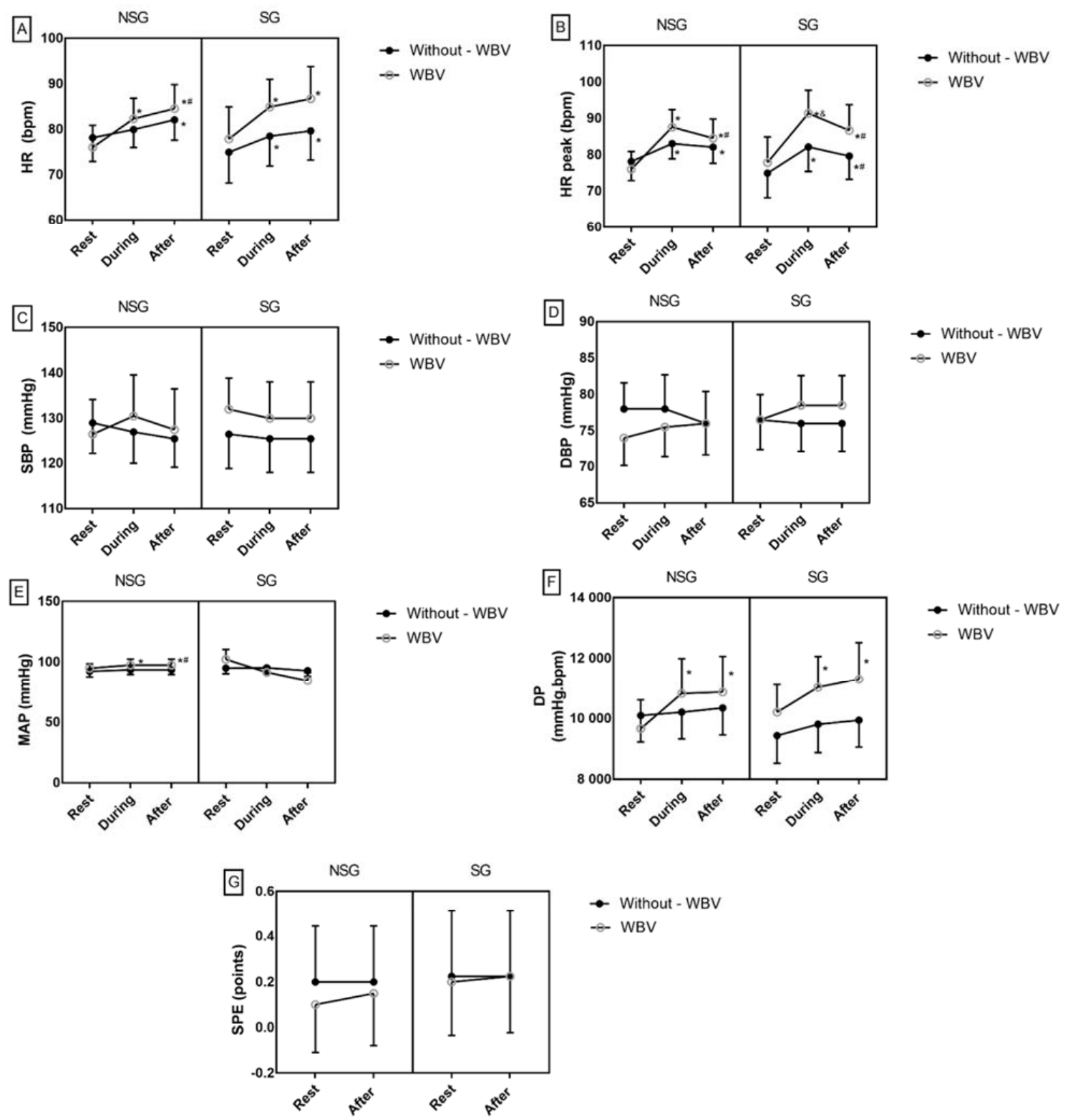

Figure 2. Immediate hemodynamic responses in the interventions with and without whole-body vibration in nonsarcopenic and sarcopenic groups. Data are means and standard deviation. Two-way ANOVA for repeated measures and post hoc Bonferroni. Significance * difference between "rest"; \# difference between "during", and \& difference between WBV vs. without WBV $(p<0.05)$. Difference between the mean values at rest between groups $(\mathrm{a} \# \mathrm{~b})$. (A)—HR: heart rate; (B) 一peak HR; (C)—Systolic Blood Pressure (SBP); (D)—Diastolic Blood Pressure (DBP); (E)—MAP: mean arterial pressure; (F)—DP: double product; $(\mathrm{G})$-SPE: subjective perception of effort.
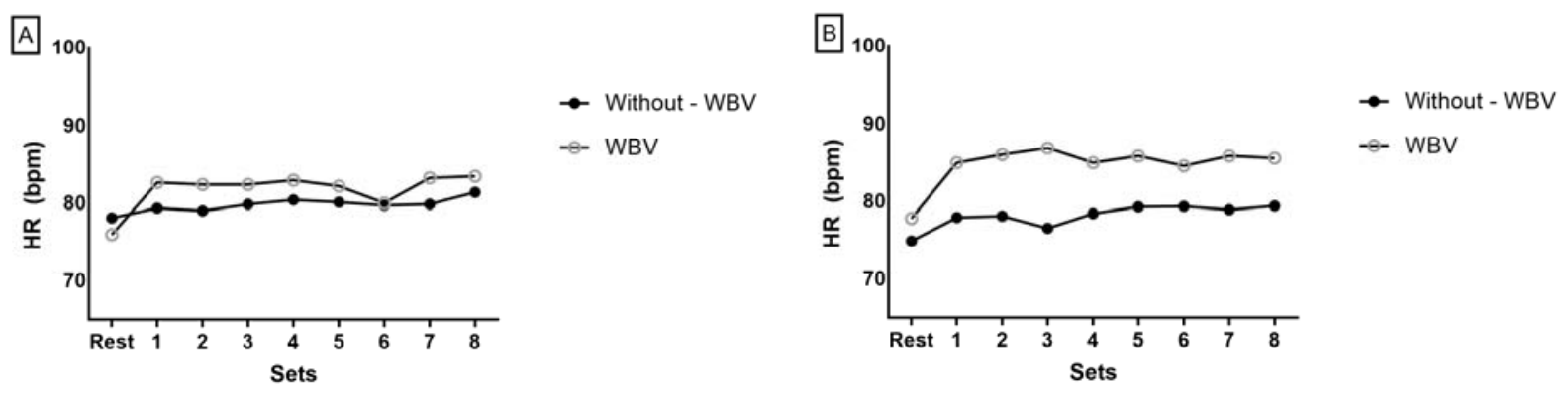

Figure 3. Heart rate (HR) behavior after each set of exercises in situations with and without whole-body vibration in the nonsarcopenic (A) and sarcopenic (B) groups. 
Table 2. Comparison of hemodynamic parameters between the interventions in the nonsarcopenic and the sarcopenic group.

\begin{tabular}{|c|c|c|c|}
\hline Outcomes & Intervention & NSG & SG \\
\hline \multirow{3}{*}{$\Delta \mathrm{HR}, \mathrm{bpm}$} & Without WBV & $1.80(-0.82-4.43)$ & $3.50(0.90-6.2)$ \\
\hline & WBV & $6.30(3.68-8.92)$ & $7.10(4.44-9.70)$ \\
\hline & Mean Difference & $4.50(0.78-8.20) *$ & $3.50(-0.177-7.24)$ \\
\hline \multirow{3}{*}{$\Delta$ peak HR, bpm } & Without WBV & $4.90(2.20-7.60)$ & $7.20(4.46-9.94)$ \\
\hline & WBV & $11.60(8.86-14.34)$ & $13.55(10.81-16.30)$ \\
\hline & Mean Difference & $6.70(2.83-10.57) *$ & $6.35(2.47-10.22) *$ \\
\hline \multirow{3}{*}{$\Delta \mathrm{SBP}, \mathrm{mmHg}$} & Without WBV & $-2.00(-6.54-2.54)$ & $-1.00(-5.54-3.54)$ \\
\hline & WBV & $4.00(-0.54-8.54)$ & $-2.00(-6.54-2.54)$ \\
\hline & Mean Difference & $6.00(-0.42-12.42)$ & $1.00(-5.42-7.42)$ \\
\hline \multirow{3}{*}{$\Delta \mathrm{DBP}, \mathrm{mmHg}$} & Without WBV & $0.00(-3.50-3.50)$ & $-0.50(-3.40-2.99)$ \\
\hline & WBV & $1.50(-1.99-4.99)$ & $2.00(-1.50-5.50)$ \\
\hline & Mean Difference & $1.50(-3.44-6.44)$ & $2.50(-2.44-7.44)$ \\
\hline \multirow{3}{*}{$\triangle \mathrm{MAP}, \mathrm{mmHg}$} & Without WBV & $0.17(-4.80-5.13)$ & $1.17(-3.80-6.13)$ \\
\hline & WBV & $-10.67(-15.63--5.70)$ & $2.66(-2.30-7.63)$ \\
\hline & Mean Difference & $-10.83(-17.85--3.81)^{*}$ & $-1.50(-8.52--5.52)$ \\
\hline \multirow{3}{*}{$\Delta \mathrm{DP}, \mathrm{mmHg}, \mathrm{bpm}$} & Without WBV & $110.60(-370.36-591.56)$ & $365.90(-115.06-846.86)$ \\
\hline & WBV & $1160.75(679.73-1641.70)$ & $822.85(341.90-1303.80)$ \\
\hline & Mean Difference & $1050.15(369.97-1730.33)$ * & $456.95(-223.23-1137.13)$ \\
\hline \multirow{3}{*}{$\triangle \mathrm{SPE}$, points } & Without WBV & $0.00(-0.05-0.05)$ & $0.00(-0.056-0.056)$ \\
\hline & WBV & $0.05(-0.006-0.106)$ & $0.02(-0.03-0.08)$ \\
\hline & Mean Difference & $-0.05(-0.13-0.03)$ & $-0.02(-0.10-0.05)$ \\
\hline
\end{tabular}

Values are means (95\% CI). HR: heart rate; peak HR: peak heart rate; systolic blood pressure (SBP); diastolic blood pressure (DBP); MAP: mean arterial pressure; DP: double product; SPE: subjective perception of effort. NSG: Nonsarcopenic group and SG: Sarcopenic group. Experimental design in randomized blocks (between-intervention, within-intervention, interaction analyses). Two-way ANOVA (2 intervention vs. 2 moments), in both groups (nonsarcopenic and sarcopenic). * Post hoc Bonferroni significance.

Table 3. Effects and interaction values found by Two-way ANOVA analysis of the data presented in Table 2.

\begin{tabular}{ccccccc}
\hline \multirow{2}{*}{ Outcomes } & \multicolumn{2}{c}{$\begin{array}{c}\text { Between Groups } \\
\text { (NSG vs. SG) }\end{array}$} & $\begin{array}{c}\text { Within Groups } \\
\text { (Without-WBV vs. WBV) }\end{array}$ & Interaction \\
\cline { 2 - 6 } & $\boldsymbol{p}$ & $\mathbf{F}$ & $\boldsymbol{p}$ & $\mathbf{F}$ & $\boldsymbol{p}$ & $\mathbf{F}$ \\
\hline$\Delta$ HR, bpm & 0.35 & 0.89 & $\mathbf{0 . 0 0 3}$ & 9.3 & 0.72 & 0.13 \\
$\Delta$ peak HR, bpm & 0.12 & 2.38 & $\mathbf{0 . 0 0 0}$ & 22.51 & 0.89 & 0.02 \\
$\Delta$ SBP, mmHg & 0.28 & 1.20 & 0.28 & 1.20 & 0.13 & 0.78 \\
$\Delta$ DBP, mmHg & 1.00 & 0.00 & 0.26 & 3.50 & $\mathbf{0 . 0 2}$ & 6.12 \\
$\Delta$ MAP, mmHg & $\mathbf{0 . 0 0 5}$ & 8.27 & 0.06 & 9.74 & 0.22 & 1.50 \\
$\Delta$ DP, mmH, bpm & 0.86 & 0.03 & $\mathbf{0 . 0 0 3}$ & 1.80 & 0.65 & 0.20 \\
$\Delta$ SPE, points & 0.65 & 0.20 & 0.18 & & \\
\hline
\end{tabular}

Legend: HR: heart rate; peak HR: peak heart rate; systolic blood pressure (SBP); diastolic blood pressure (DBP); MAP: mean arterial pressure; DP: double product; SPE: subjective perception of effort. NSG: Nonsarcopenic group and SG: Sarcopenic group. Experimental design in randomized blocks (between-intervention, within-intervention, interaction analyses). Two-way ANOVA ( 2 intervention vs. 2 moments), in both groups (nonsarcopenic and sarcopenic). Bold values denote statistical significance at the $p<0.05$ level.

\section{Discussion}

To the best of our knowledge, this is the first study to investigate the immediate effects of a WBV session on hemodynamic parameters in the context of sarcopenia. This study demonstrated that the addition of WBV promoted greater variations in hemodynamic variables compared to the squatting exercise alone. However, both groups had the same behavior, proving that it is a safe procedure for individuals with sarcopenia.

As expected, individuals with sarcopenia had low values for anthropometric and body composition variables, which is a similar result to findings from other studies in different 
populations [42,43], as sarcopenic individuals generally present worse lower-limb muscle performance $[44,45]$. Despite the differences found, the results of functional tests are within normal cutoff values (EWGSOP) [1].

For the execution of the WBV exercise, a frequency of $40 \mathrm{~Hz}$ combined with an intermittent duration close to $360 \mathrm{~s}$ per session was used. The choice of the vibration parameters was in line with effective parameters to improve and preserve physical performance in older people with sarcopenia [46,47]. Moreover, the parameters are preferable for stimulating muscles while limiting fatigue [27].

The results showed that one exercise session with WBV was able to increase the mean HR of individuals with sarcopenia and nonsarcopenic individuals. Nonetheless, the addition of vibration promoted a greater variation in HR when compared to the dynamic squatting exercise alone. Similar behavior was observed for peak HR, mainly during the vibration exercise. The findings of this study corroborate the studies of Avelar et al. [26] and Cochrane et al. [27], in which a significant increase in HR was found during WBV exercise compared with exercise without vibration in sedentary older people.

These cardiovascular responses seem to be the result of adding vibration, which induces changes in tissues leading to the activation of muscle spindles, causing a reflex contraction to modulate the stiffness of the muscles involved known as the tonic vibration reflex [48]. This promotes an increase in muscle perfusion associated with peripheral vasodilation where muscle activation occurs, especially in lower limbs. Moreover, the increase in ejection volume due to the increase in venous return is a factor that may be related to the regulation of acute adaptations to exercise, such as the increase in cardiac output and the consequent increase in HR $[49,50]$.

In dynamic exercises, with a greater volumetric load in the left ventricle, the cardiac and hemodynamic responses are proportional to the intensity and muscle mass involved in the activity [51]. Our data demonstrated that WBV was performed at an intensity corresponding to $57 \%$ and $59 \%$ of the maximum heart rate (HRmax) predicted for age in sarcopenic older people, for mean HR and peak HR, respectively. These values were close to those recommended by the American College of Sports Medicine (ACMS) [52] and the American Heart Association [53], which consider around $60 \%$ of HRmax sufficient to promote cardiovascular physiological changes in sedentary older people [54]. Although exposure to vibration increased the mean HR and peak HR in both groups, the intensity used was mild (light exertion intensity, 57-63\% of HRmax predicted for age) [52]. These results are in agreement with a study by Ribeiro et al. [32] that used the same exercise protocol proposed in the present study, in which the WBV, even at low intensity, promoted similar cardiorespiratory changes in healthy people and those with fibromyalgia. According to Licurci et al. [55], older people have a higher risk of developing cardiovascular diseases. As demonstrated in their study, a single session of WBV promoted an improvement in heart rate variability. Moreover, they concluded that WBV does not require physical effort, which makes it potentially beneficial for this population.

In addition to peak HR, SPE and DP are important parameters for monitoring intensity in different exercise modalities [56]. Although differences were observed in hemodynamic variables in the present study, these differences did not cause an increase in SPE, whereby individuals classified the WBV exercise as mild and the vibration did not cause fatigue. Studies have shown that, in addition to exercise intensity, SPE may reflect sensitivity to fatigue related to active musculature during exercise [57]. The addition of WBV increased DP, nevertheless the maximum value for DP during the vibration exercise did not exceed the myocardial ischemia threshold, which is above $30,000 \mathrm{mmHg} \cdot \mathrm{bpm}$ and is considered as the cutoff point for angina pectoris [58], showing that the acute exercise protocol with WBV was of low cardiac risk for sarcopenic older people. Moreover, the HR behavior observed in our study during WBV reinforces the safety of the vibration exercise. All patients completed the WBV protocol without adverse effects during the intervention. A study by Aoyama et al. [59] demonstrated that older people with cardiovascular diseases did not present adverse events after an acute session of WBV. 
In our findings, the addition of vibration did not promote significant changes in SBP and DBP in either group when compared to the squatting exercise without WBV. In addition to the low exercise intensity, in each NSG and SG, $45 \%$ of the participants were hypertensive, being equally distributed in the two groups, which may help to explain the absence of differences in these hemodynamic variables [10]. This result is clinically important because SBP and DBP are determinants of ventricular load and myocardial perfusion pressure, respectively, thus they are more relevant predictors of cardiovascular events [60].

In the NSG, there was a significant increase in MAP during and immediately after vibration exercise. This increase in MAP can be explained by the vibration, which increases muscle stimulation [61], associated with the dynamic squatting exercise, and can potentialize the effect and significantly stimulate the cardiovascular system, increasing HR, blood flow [62], and blood volume [63,64]. These increases may be related to the contractionrelaxation reflex stimulated by vibration, causing greater muscle mass to be recruited (such as the trunk muscles) to allow the individual to continue exercising [65]. The attenuated MAP responses in the SG can be explained as a function of low muscle mass, inadequate supply of blood flow, and, consequently, low capillarization of the skeletal muscle present in sarcopenia [7].

Despite the promising results, the present study has some limitations. We acknowledged that despite being sarcopenic, the older people participating in the study were living in the community and were independent, which may have impacted the severity of the disease, and thus, the magnitude of the physical functions and the effects of the interventions. Therefore, further studies involving a spectrum of sarcopenia-severity patients are warranted. Although the number of participants was based on sample size calculation, the low sample size may have influenced the absence of significant statistical differences for some variables and limited the possibility for extrapolations from the current findings.

The strengths and applications of the findings of this study are that the effects during and immediately after a short session of low-intensity WBV exercise induces safe changes in hemodynamic parameters in sarcopenic older people. Moreover, it showed good adherence from the study participants, and its application in sarcopenic older people who are reluctant to practice physical exercise may be of interest.

\section{Conclusions}

WBV exercise induces safe changes in hemodynamic parameters in sarcopenic older people. The absence of adverse effects of WBV exercise on the cardiovascular system and fatigue shows that this exercise modality can be considered for sarcopenic older people. However, the long-term effects of the WBV need to be studied in this population.

Author Contributions: Conceptualization: F.A.d.P., V.A.M., V.K.d.S.L., A.C.R.L.; Methodology: F.A.d.P., V.A.M., V.K.d.S.L., G.P.d.S., H.C.d.A., L.P.L., J.N.V.S., A.C.R.L.; Formal analysis: F.A.d.P., V.K.d.S.L., V.C.d.O., P.H.S.F., M.B.-F., R.T.; Investigation: F.A.d.P., V.K.d.S.L., G.P.d.S., H.C.d.A., L.P.L., J.N.V.S., D.P.d.C., C.F.d.P., A.L.d.S.N.T.R.; Writing (original draft, review, and editing): F.A.d.P., V.A.M., V.K.d.S.L., G.P.d.S., H.C.d.A., L.P.L., J.N.V.S.; Writing (review and editing): A.C.R.L., V.C.d.O., P.H.S.F., M.B.-F., R.T.; Supervision: F.A.d.P., V.A.M. All authors have read and agreed to the published version of the manuscript.

Funding: This research received no external funding.

Institutional Review Board Statement: The study was conducted according to the guidelines of the Declaration of Helsinki, and Resolution No. 466/12 of the National Health Council and approved by the Ethics Committee of the Universidade Federal dos Vales do Jequitinhonha e Mucuri, Identification No. 74422817.1.0000.5108) and registered with the Brazilian Clinical Trials Registry (REBEC; RBR$35 \mathrm{w} 9 \mathrm{bw})$.

Informed Consent Statement: Informed consent was obtained from all participants involved in the study. 
Data Availability Statement: The data presented in this study are available on reasonable request from the corresponding author.

Acknowledgments: The authors thank the Centro Integrado de Pós-Graduação e Pesquisa em Saúde at the Universidade Federal dos Vales do Jequitinhonha e Mucuri, Diamantina, MG, for providing equipment and technical support for the experiments. This study was supported by the Fundação de Amparo à Pesquisa do Estado de Minas Gerais (FAPEMIG APQ-01328-18), Conselho Nacional de Desenvolvimento Científico e Tecnológico-CNPq (CNPq-426952/2018-9), and the Coordenação de Aperfeiçoamento de Pessoal de Nível Superior (Capes).

Conflicts of Interest: The authors declare no conflict of interest. The funders had no role in the design of the study; in data collection, analyses, or interpretation; in the writing of the manuscript, or in the decision to publish the results.

\section{References}

1. Cruz-Jentoft, A.J.; Bahat, G.; Bauer, J.; Boirie, Y.; Bruyère, O.; Cederholm, T.; Cooper, C.; Landi, F.; Rolland, Y.; Sayer, A.A.; et al. Sarcopenia: Revised European consensus on definition and diagnosis. Age Ageing 2019, 48, 16-31. [CrossRef] [PubMed]

2. Norman, K.; Otten, L. Financial impact of sarcopenia or low muscle mass-A short review. Clin. Nutr. 2019, 38, 1489-1495. [CrossRef] [PubMed]

3. Cruz-Jentoft, A.J.; Sayer, A.A. Sarcopenia. Lancet 2019, 393, 2636-2646. [CrossRef]

4. Churilov, I.; Churilov, L.; MacIsaac, R.J.; Ekinci, E.I. Systematic review and meta-analysis of prevalence of sarcopenia in post acute inpatient rehabilitation. Osteoporos. Int. 2018, 29, 805-812. [CrossRef]

5. Cruz-Jentoft, A.J.; Landi, F.; Schneider, S.M.; Zúñiga, C.; Arai, H.; Boirie, Y.; Chen, L.K.; Fielding, R.A.; Martin, F.C.; Michel, J.; et al. Prevalence of and interventions for sarcopenia in ageing adults: A systematic review. Report of the International Sarcopenia Initiative (EWGSOP and IWGS). Age Ageing 2014, 43, 48-759. [CrossRef] [PubMed]

6. Beaudart, C.; Zaaria, M.; Pasleau, F.; Reginster, J.Y.; Bruyère, O. Health outcomes of sarcopenia: A systematic review and meta-analysis. PLoS ONE 2017, 12, e0169548. [CrossRef]

7. Kim, I.; Kang, G.; Yoon, J.; Kim, W.; Kim, H. Relationship between within-visit blood pressure variability and skeletal muscle mass. J. Nutr. Health Aging 2019, 23, 79-83. [CrossRef]

8. Investigations, O. Diastolic Blood Pressure, Subclinical Myocardial Damage, and Cardiac Events. J. Am. Coll. Cardiol. 2016, 68, 1713-1722. [CrossRef]

9. Muller, M.D.; Gao, Z.; Mast, J.L.; Blaha, C.A.; Drew, R.C.; Leuenberger, U.A.; Sinoway, L.I. Aging attenuates the coronary blood flow response to cold air breathing and isometric handgrip in healthy humans. Am. J. Physiol.-Heart Circ. Physiol. 2012, 302, H1737-H1746. [CrossRef]

10. Wong, A.; Jaime, S.J.; Grubbs, B.; Panton, L.B.; Fischer, S.M. Attenuated aortic blood pressure responses to metaboreflex activation in older adults with dynapenia. Exp. Gerontol. 2020, 138, 110984. [CrossRef]

11. Curcio, F.; Testa, G.; Liguori, I.; Papillo, M.; Flocco, V.; Panicara, V.; Galizia, G.; Della-Morte, D.; Gargiulo, G.; Cacciatore, F.; et al. Sarcopenia and heart failure. Nutrients 2020, 12, 211. [CrossRef]

12. Calvani, R.; Marini, F.; Cesari, M.; Tosato, M.; Anker, S.D.; Von Haehling, S.; Miller, R.R.; Bernabei, R.; Landi, F.; Marzetti, E. Biomarkers for physical frailty and sarcopenia: State of the science and future developments. J. Cachexia. Sarcopenia Muscle 2015, 6, 278-286. [CrossRef] [PubMed]

13. Wesley, G.; Rodrigues, M.; De Souza, F.R.; Jose, M.; Costa, A.; Von Haehling, S.; Takayama, L.; Pereira, R.M.R.; Negrão, C.E.; Anker, S.D.; et al. Original Article Sympatho-Vagal Imbalance is Associated with Sarcopenia in Male Patients with Heart Failure. Arq. Bras. Cardiol. 2018, 112, 739-746. [CrossRef]

14. Yanaga, M.C. Sarcopenia em Idosos: Um estudo de revisão. Int. J. Nutrol. 2020, 13, 089-094. [CrossRef]

15. Rolland, Y.; Czerwinski, S.; Van Kan, G.A.; Morley, J.E.; Cesari, M.; Onder, G.; Woo, J.; Baumgartner, R.; Pillard, F.; Boirie, Y.; et al. Sarcopenia: Its assessment, etiology, pathogenesis, consequences and future perspectives. J. Nutr. Health Aging 2008, 12, 433-450. [CrossRef]

16. Visvanathan, R.; Chapman, I. Preventing sarcopaenia in older people. Maturitas 2010, 66, 383-388. [CrossRef]

17. Nelson, M.E.; Rejeski, W.J.; Blair, S.N.; Duncan, P.W.; Judge, J.O.; King, A.C.; Macera, C.A.; Castaneda-Sceppa, C. Physical activity and public health in older adults: Recommendation from the American College of Sports Medicine and the American Heart Association. Med. Sci. Sports Exerc. 2007, 39, 1435-1445. [CrossRef]

18. Morley, J.E. Pharmacologic Options for the Treatment of Sarcopenia. Calcif. Tissue Int. 2016, 98, 319-333. [CrossRef]

19. Valenzuela, P.L.; Castillo-García, A.; Morales, J.S.; Izquierdo, M.; Serra-Rexach, J.A.; Santos-Lozano, A.; Lucia, A. Physical exercise in the oldest old. Compr. Physiol. 2019, 9, 1281-1304. [CrossRef]

20. Rittweger, J. Vibration as an exercise modality: How it may work, and what its potential might be. Eur. J. Appl. Physiol. 2010, 108, 877-904. [CrossRef]

21. Freitas, E.D.S.; Frederiksen, C.; Miller, R.M.; Heishman, A.; Anderson, M.; Pardo, G.; Fjeldstad, C.; Bemben, D.A.; Bemben, M.G. Acute and Chronic Effects of Whole-Body Vibration on Balance, Postural Stability, and Mobility in Women With Multiple Sclerosis. Dose-Response 2018, 16, 1559325818816577. [CrossRef] 
22. Lam, F.M.H.; Liao, L.R.; Kwok, T.C.Y.; Pang, M.Y.C. The effect of vertical whole-body vibration on lower limb muscle activation in elderly adults: Influence of vibration frequency, amplitude and exercise. Maturitas 2016, 88, 59-64. [CrossRef] [PubMed]

23. Kemmler, W.; Von Stengel, S. Alternative Exercise Technologies to Fight against Sarcopenia at Old Age: A Series of Studies and Review. J. Aging Res. 2012, 2012, 109013. [CrossRef]

24. Thompson, W.R.; Yen, S.S.; Rubin, J. Vibration therapy: Clinical applications in bone. Curr. Opin. Endocrinol. Diabetes Obes. 2014 21, 447-453. [CrossRef] [PubMed]

25. Zhu, Y.Q.; Peng, N.; Zhou, M.; Liu, P.P.; Qi, X.L.; Wang, N.; Wang, G.; Wu, Z.P. Tai Chi and whole-body vibrating therapy in sarcopenic men in advanced old age: A clinical randomized controlled trial. Eur. J. Ageing 2019, 16, 273-282. [CrossRef] [PubMed]

26. Avelar, N.C.P.; Simão, A.P.; Tossige-Gomes, R.; Neves, C.D.C.; Mezencio, B.; Szmuchrowski, L.; Coimbra, C.C.; Lacerda, A.C.R. Oxygen consumption and heart rate during repeated squatting exercises with or without whole-body vibration in the elderly. $J$. Strength Cond. Res. 2011, 25, 3495-3500. [CrossRef] [PubMed]

27. Cochrane, D.J.; North, P.; Zealand, N.; Drive, T.; Zealand, N. Vibration Exercise: The Potential Benefits. Int. J. Sports Med. 2011, 32, 75-99. [CrossRef]

28. Cochrane, D.J.; Sartor, F.; Winwood, K.; Stannard, S.R.; Narici, M.V.; Rittweger, J. A Comparison of the Physiologic Effects of Acute Whole-Body Vibration Exercise in Young and Older People. Arch. Phys. Med. Rehabil. 2008, 89, 815-821. [CrossRef]

29. Lage, V.K.S.; Lacerda, A.C.R.; Neves, C.D.C.; Chaves, M.G.A.; Soares, A.A.; Lima, L.P.; Matos, M.A.; Leite, H.R.; Fernandes, J.S.C.; Oliveira, V.C.; et al. Cardiorespiratory responses in different types of squats and frequencies of whole body vibration in patients with chronic obstructive pulmonary disease. J. Appl. Physiol. 2019, 126, 23-29. [CrossRef] [PubMed]

30. Sá-Caputo, D.C.; Paineiras-Domingos, L.L.; Oliveira, R.; Neves, M.F.T.; Brandão, A.; Marin, P.J.; Sañudo, B.; Furness, T.; Taiar, R.; Bernardo-Filho, M. Acute Effects of Whole-Body Vibration on the Pain Level, Flexibility, and Cardiovascular Responses in Individuals With Metabolic Syndrome. Dose-Response 2018, 16, 1559325818802139. [CrossRef] [PubMed]

31. Bautmans, I.; Van Hees, E.; Lemper, J.C.; Mets, T. The feasibility of whole body vibration in institutionalised elderly persons and its influence on muscle performance, balance and mobility: A randomised controlled trial [ISRCTN62535013]. BMC Geriatr. 2005, 5, 17. [CrossRef] [PubMed]

32. Ribeiro, V.G.C.; Mendonça, V.A.; Souza, A.L.C.; Fonseca, S.F.; Camargos, A.C.R.; Lage, V.K.S.; Neves, C.D.C.; Santos, J.M.; Teixeira, L.A.C.; Vieira, E.L.M.; et al. Inflammatory biomarkers responses after acute whole body vibration in fibromyalgia. Braz. J. Med. Biol. Res. 2018, 51, 1-9. [CrossRef]

33. Gould, H.; Brennan, S.L.; Kotowicz, M.A.; Nicholson, G.C.; Pasco, J.A. Total and appendicular lean mass reference ranges for Australian men and women: The Geelong osteoporosis study. Calcif. Tissue Int. 2014, 94, 363-372. [CrossRef] [PubMed]

34. Cervi, A.; Franceschini, S.D.C.C.; Priore, S.E. Análise crítica do uso do índice de massa corporal para idosos. Rev. Nutr. 2005, 18, 765-775. [CrossRef]

35. Guralnik, J.M.; Simonsick, E.M.; Ferrucci, L.; Glynn, R.J.; Berkman, L.F.; Blazer, D.G.; Scherr, P.A.; Wallace, R.B. A Short Physical Performance Battery Assessing Lower Extremity Function: Association with Self-Reported Disability and Prediction of Mortality and Nursing Home Admission. J. Gerontol. 1994, 49, 85-94. [CrossRef]

36. Avelar, N.C.P.; Ribeiro, V.G.C.; Mezêncio, B.; Fonseca, S.F.; Tossige-Gomes, R.; da Costa, S.J.; Szmuchrowski, L.; Gripp, F.; Coimbra, C.C.; Lacerda, A.C.R. Influence of the knee flexion on muscle activation and transmissibility during whole body vibration. J. Electromyogr. Kinesiol. 2013, 23, 844-850. [CrossRef]

37. Brum, P.C.; de M Forjaz, C.L.; Tinucci, T.; Negrão, C.E. Adaptações agudas e crônicas do exercício físico no sistema cardiovascular. Rev. Paul. Educ. Fís. 2004, 18, 21-31.

38. Miranda, H.; Simão, R.; Lemos, A.; Dantas, B.H.A.; Baptista, L.A.; Novaes, J. Análise de freqüência cardíaca, pressão arterial e duplo-produto em diferentes posições corporais nos exercícios resistidos. Rev. Bras. Med. Esporte 2005, 11, 295-298. [CrossRef]

39. Tibana, R.; Balsamo, S.; Prestes, J. Association between muscle strength and at-rest blood pressure among sedentary women. Int. J. Cardiovasc. Sci. 2011, 24, 163-168.

40. Robergs, R. JEP Online Journal of Exercise Physiology Online. 2014. Available online: https://d1wqtxts1xzle7.cloudfront. net/33678326/ENERGY_COST_AND_PHYSIOLOGICAL_EFFICIENCY_IN_MALE_YOGA_PRACTITIONERS.pdf?13998788 94=\&response-content-disposition=inline\%3B+filename\%3DENERGY_COST_AND_PHYSIOLOGICAL_EFFICIENCY.pdf\& Expires=1636340622\&Signature=Felqh2JJJUuoFQr7AYwYyggMpBmLG \{\}QQCJymo474e6aOoMK4cEZUGioYuDJfwqhU137 ofFD8xmsfb6TPc-vfZKmkb \{\}x8L85uANDulEKA012lk9cIXYgmR611LBhfuGgnAosw8A9XUUB \{\}u176LjOBs1qg4hcaOh6 ticjKH \{\}dLbfbq5m \{\}BZZHGK0yRYANoF1ZmtYdJuHfulhRWyKmqUz8qXLq-awRChScmrFZPn \{\}E \{\}JXN5eYmOqNy9 67C8BQp2VhkpjTnAlAyjrPvhvoGuICIG4rGLE71ZmG0stLpA \{\}zDoPOM5QukTsPlCC7Lx2EZjcVOuHX0bKWJf050An-jK0 xcqqA_\&Key-Pair-Id=APKAJLOHF5GGSLRBV4ZA (accessed on 24 August 2021).

41. Borg, G.A. Psychophysical bases of perceived exertion. Med. Sci. Sports Exerc. 1982, 14, 377-381. [CrossRef]

42. Liu, C.K.; Leng, X.; Hsu, F.C.; Kritchevsky, S.B.; Ding, J.; Earnest, C.P.; Ferrucci, L.; Goodpaster, B.H.; Guralnik, J.M.; Lenchik, L.; et al. The impact of sarcopenia on a physical activity intervention: The lifestyle interventions and independence for elders pilot study (LIFE-P). J. Nutr. Health Aging 2014, 18, 59-64. [CrossRef]

43. Verlaan, S.; Aspray, T.J.; Bauer, J.M.; Cederholm, T.; Hemsworth, J.; Hill, T.R.; McPhee, J.S.; Piasecki, M.; Seal, C.; Sieber, C.C.; et al. Nutritional status, body composition, and quality of life in community-dwelling sarcopenic and non-sarcopenic older adults: A case-control study. Clin. Nutr. 2017, 36, 267-274. [CrossRef] [PubMed] 
44. Yamada, M.; Nishiguchi, S.; Fukutani, N.; Tanigawa, T.; Yukutake, T.; Kayama, H.; Aoyama, T.; Arai, H. Prevalence of sarcopenia in community-dwelling Japanese older adults. J. Am. Med. Dir. Assoc. 2013, 14, 911-915. [CrossRef] [PubMed]

45. He, L.; Khanal, P.; Morse, C.I.; Williams, A.; Thomis, M. Differentially methylated gene patterns between age-matched sarcopenic and non-sarcopenic women. J. Cachexia Sarcopenia Muscle 2019, 10, 1295-1306. [CrossRef]

46. Miller, R.M.; Heishman, A.D.; Freitas, E.D.S.; Bemben, M.G. Comparing the acute effects of intermittent and continuous whole-body vibration exposure on neuromuscular and functional measures in sarcopenia and nonsarcopenic elderly women. Dose-Response 2018, 16, 1559325818797009. [CrossRef] [PubMed]

47. Wei, N.; Pang, M.Y.C.; Ng, S.S.M.; Ng, G.Y.F. Optimal frequency/time combination of whole body vibration training for developing physical performance of people with sarcopenia: A randomized controlled trial. Clin. Rehabil. 2017, 31, 1313-1321. [CrossRef]

48. David, S.; Filho, S.; Bernardo, R.M.; Santos, F.A.; Meyer, P.F.; Ronzio, O.A.; Speranza, S.; Guedes, V.; Gass, R.; Cardoso, D.M.; et al. Exercícios de vibração de corpo inteiro em plataformas vibratórias: Interesse Científico. Saúde 2015, 41, 19-26.

49. Rittweger, J.; Beller, G.; Felsenberg, D. Acute physiological effects of exhaustive whole-body vibration exercise in man. Clin. Physiol. 2000, 20, 134-142. [CrossRef]

50. Hazell, T.J.; Thomas, G.W.R.; DeGuire, J.R.; Lemon, P.W.R. Vertical whole-body vibration does not increase cardiovascular stress to static semi-squat exercise. Eur. J. Appl. Physiol. 2008, 104, 903-908. [CrossRef]

51. Polito, M.D.; Farinatti, P.T.V. Respostas de frequência cardíaca, pressão arterial e duplo-produto ao exercício contra-resistência: Uma revisão da literatura. Rev. Port. Ciências Desporto 2003, 2003, 79-91. [CrossRef]

52. Garber, C.E.; Blissmer, B.; Deschenes, M.R.; Franklin, B.A.; Lamonte, M.J.; Lee, I.M.; Nieman, D.C.; Swain, D.P. Quantity and quality of exercise for developing and maintaining cardiorespiratory, musculoskeletal, and neuromotor fitness in apparently healthy adults: Guidance for prescribing exercise. Med. Sci. Sports Exerc. 2011, 43, 1334-1359. [CrossRef]

53. American Heart Association. Diretrizes de RCP e ACE.; American Heart Association: Chicago, IL, USA, 2020 ; Volume 32.

54. Dias, T.; Polito, M. Acute Cardiovascular Response during Resistance Exercise with Whole-body Vibration in Sedentary Subjects: A Randomized Cross-over Trial. Res. Sport. Med. 2015, 23, 253-264. [CrossRef] [PubMed]

55. Bastos, G.; Fagundes, A.D.A.; Angela, E.; Schiavo, L. Journal of Bodywork \& Movement Therapies Acute effects of whole body vibration on heart rate variability in elderly people. J. Bodyw. Mov. Ther. 2018, 22, 618-621. [CrossRef]

56. Pinheiro, F.A.; Viana, B.; Pires, F.O. Ratings of perceived exertion as an indicator of the tolerable exercise duration. Motricidade 2014, 10, 100-106. [CrossRef]

57. Monteiro, W.; Simão, R.; Farinatti, P. Manipulação na ordem dos exercícios e sua influência sobre número de repetições e percepção subjetiva de esforço em mulheres treinadas. Rev. Bras. Med. Esporte 2005, 11, 146-150. [CrossRef]

58. Fornitano, L.D.; De Godoy, M.F. Increased rate-pressure product as predictor for the absence of significant obstructive coronary artery disease in patients with positive exercise test. Arq. Bras. Cardiol. 2006, 86, 138-144. [CrossRef]

59. Aoyama, A.; Yamaoka-Tojo, M.; Obara, S.; Shimizu, E.; Fujiyoshi, K.; Noda, C.; Matsunaga, A.; Ako, J. Acute effects of wholebody vibration training on endothelial function and cardiovascular response in elderly patients with cardiovascular disease: A single-arm pilot study. Int. Heart J. 2019, 60, 854-861. [CrossRef]

60. Vlachopoulos, C.; Aznaouridis, K.; Rourke, M.F.O.; Safar, M.E.; Baou, K.; Stefanadis, C. Prediction of cardiovascular events and all-cause mortality with central haemodynamics: A systematic review and metaanalysis. Eur. Heart J. 2010, 31, $1865-1871$. [CrossRef]

61. Cardinale, M.; Bosco, C. The use of vibration as an exercise intervention. Exerc. Sport Sci. Rev. 2003, 31, 3-7. [CrossRef] [PubMed]

62. Lythgo, N.; Eser, P.; De Groot, P.; Galea, M. Whole-body vibration dosage alters leg blood flow. Clin. Physiol. Funct. Imaging 2009, 29, 53-59. [CrossRef]

63. Kerschan-Schindl, K.; Grampp, S.; Henk, C.; Resch, H.; Preisinger, E.; Fialka-Moser, V.; Imhof, H. Whole-body vibration exercise leads to alterations in muscle blood volume. Clin. Physiol. 2001, 21, 377-382. [CrossRef] [PubMed]

64. Maloney-Hinds, C.; Petrofsky, J.S.; Zimmerman, G.; Hessinger, D.A. The Role of Nitric Oxide in Skin Blood Flow Increases Due to Vibration in Healthy Adults and Adults with Type 2 Diabetes. Diabetes Technol. Ther. 2009, 11, 39-43. [CrossRef] [PubMed]

65. Ye, J.; Ng, G.; Yuen, K. Acute effects of whole-body vibration on trunk muscle functioning in young healthy adults. J. Strength Cond. Res. 2014, 28, 2872-2879. [CrossRef] [PubMed] 